\title{
Oceanography
}

CITATION

Foster, R. 2013. Signature of large aspect ratio roll vortices in synthetic aperture radar images of tropical cyclones. Oceanography 26(2):58-67, http://dx.doi.org/10.5670/oceanog.2013.31.

$\mathrm{DOI}$

http://dx.doi.org/10.5670/oceanog.2013.31

COPYRIGHT

This article has been published in Oceanography, Volume 26, Number 2, a quarterly journal of The Oceanography Society. Copyright 2013 by The Oceanography Society. All rights reserved.

USAGE

Permission is granted to copy this article for use in teaching and research. Republication, systematic reproduction, or collective redistribution of any portion of this article by photocopy machine, reposting, or other means is permitted only with the approval of The Oceanography Society. Send all correspondence to: info@tos.org or The Oceanography Society, PO Box 1931, Rockville, MD 20849-1931, USA. 


\section{Signature of Large Aspect Ratio Roll Vortices in Synthetic Aperture Radar Images BY RALPH FOSTER of Tropical Cyclones}

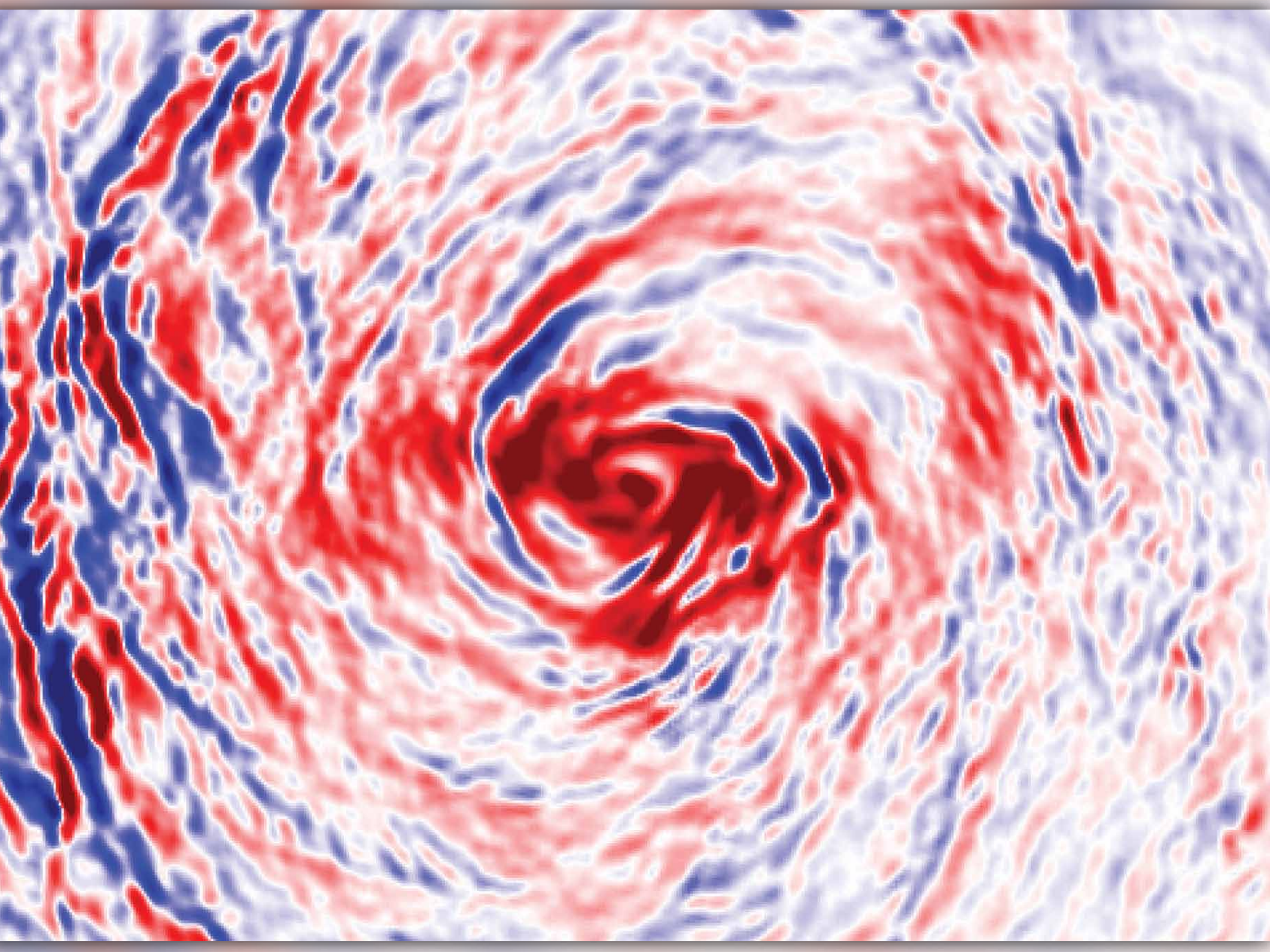

Wind stress curl for Hurricane Earl calculated from a RADARSAT-2 image taken September 2, 2010, 23:00 UTC. 
ABSTRACT. Synthetic aperture radar images of tropical cyclones have been processed into high-resolution surface wind vector fields. Examination of the surface wind divergence and wind stress curl show that wind-aligned, $O(10 \mathrm{~km})$ wavelength, banded features are present throughout the images. These signatures are consistent with what would be expected from boundary layer roll vortices, except that their wavelengths are much too large. This paper argues that large aspect ratio roll vortices are responsible for these surface wind signatures and proposes a mechanism by which they are likely formed.

\section{INTRODUCTION}

Recent advances in synthetic aperture radar (SAR) wind processing (Horstmann et al., 2013) have made it possible to generate reliable surface wind vector images at $1 \mathrm{~km}$ spacing in tropical cyclones. The surface wind vectors, $\boldsymbol{U}_{10}$, are referenced at the nominal $10 \mathrm{~m}$ height above the sea surface and corrected to neutral-equivalent stratification. (What follows will generically refer to tropical cyclones as hurricanes, although the features discussed are present in both hurricane and typhoon SAR imagery.) The unprecedented spatial resolution and coverage of SAR wind fields provide a new view of air-sea interaction in hurricanes that suggests the surface wind is highly organized at much larger spatial scales than the usual turbulence length scale based on the boundary layer depth.

Examination of the surface kinematic wind stress curl (WSC, $\nabla \times C_{D}\left|U_{10}\right| U_{10}$ ) and divergence (DIV, $\left.\nabla \cdot U_{10}\right)$ calculated from SAR images routinely shows approximately wind-aligned spatially periodic patterns of surface wind convergence/divergence pairs and positive and negative WSC. The wavelength, $\lambda$, of these patterns is around 8 to $15 \mathrm{~km}$, compared to typical hurricane boundary layer depths, $h$, of about $1 \mathrm{~km}$. These
WSC and DIV patterns suggest that there are embedded, approximately wind-aligned, $\lambda \sim O(10 \mathrm{~km})$ structures in the hurricane boundary layer that induce both: (1) periodic enhancements and reductions of the approximately azimuthal component of the surface wind and (2) periodic enhancements and reductions of the approximately radial component of the surface wind.

A similar startling discovery was made about 15 years ago. Wurman and Winslow (1998) found the near-surface hurricane boundary layer after landfall to be characterized by intense, organized, approximately wind-aligned roll vortices whose wavelength scaled with the depth of the boundary layer. Further observational studies confirmed that boundary layer roll vortices, with aspect ratios $\lambda / h \sim 2.4$ to 4 , are quite common in hurricane boundary layers (Katsaros et al., 2002; Morrison et al., 2005; Lorsolo et al., 2008; Zhang et al., 2008; Ellis and Businger, 2010). The dominant surface wind manifestation of such rolls would be banded DIV and WSC patterns with wavelengths that match the roll wavelength of $O(1-3) \mathrm{km}$. The new largewavelength signatures in surface wind DIV and WSC would be consistent with the effects of boundary layer roll vortices if it were possible to form rolls with such large aspect ratios.

The new SAR observations may be a surface signature for a previously unexplained set of Doppler radar analyses of the upper boundary layer/lower troposphere wind in land-falling hurricanes (Gall et al., 1998). These observations found ubiquitous signatures in the wind that are strikingly similar to those in the SAR images. The approximate wavelength of the Doppler radar patterns was $O(10 \mathrm{~km})$. Gall et al. (1998) hypothesized that these low-level (but well above the surface) wind patterns are present in all strong hurricanes. Furthermore, they noted that the observed features had the characteristics of very large wavelength roll vortices. However, they properly noted that the very long wavelengths and penetration above the boundary layer was not consistent with standard atmospheric boundary layer roll vortices.

The question naturally arises of how to reconcile previous observations and theoretical modeling of low aspect ratio hurricane rolls with these new observations that strongly imply the existence of large aspect ratio rolls extending down to the sea surface. A likely physical mechanism is that a secondary instability of the dominant primary roll modes generates an upscale transfer of energy into large aspect ratio roll modes. In the absence of a mechanism to energize them, such large aspect ratio rolls would not form (Foster, 2005).

Ralph Foster (ralph@apl.washington.edu) is Senior Physicist, Applied Physics Laboratory, University of Washington, Seattle, WA, USA. 


\section{STANDARD PLANETARY}

\section{BOUNDARY LAYER ROLL}

\section{VORTICES}

The marine planetary boundary layer (PBL) is the generally turbulent lowest layer of the atmosphere that exchanges energy and momentum with the ocean. The depth of the PBL depends on local atmospheric conditions, but is usually between 0.5 and $2 \mathrm{~km}$. Over most of the ocean, the sea surface temperature (SST) is slightly warmer than the near-surface air temperature, $T_{\text {air }}$, and the typical surface wind speed is about $7 \mathrm{~m} \mathrm{~s}^{-1}$. Thus, the ocean tends to warm and moisten the PBL (upward fluxes of sensible and latent heat that are approximately $20 \mathrm{~W} \mathrm{~m}^{-2}$ and $80 \mathrm{~W} \mathrm{~m}^{-2}$, respectively), and the wind transfers momentum into the ocean $(\sim 0.06 \mathrm{~Pa})$. This means that the marine PBL is usually slightly to moderately unstably stratified.

In such conditions, it is well known that the PBL turbulence forms organized large eddies (OLE) in the form of roll vortices (e.g., LeMone, 1973, 1976; Brown, 1980; Etling and Brown, 1993; Foster, 1996; Young et al., 2002.). PBL rolls are spatially periodic, quasiequilibrium embedded secondary circulations that span the depth of the boundary layer (Figure 1). The axes of the rolls tend to align in a direction between that of the surface wind and the wind above the boundary layer. We can imagine a roll-oriented coordinate system in which the $\mathrm{x}$-axis is along that of the rolls pointing in the general direction of the mean surface wind, the $y$-axis is perpendicular to the roll axis, and the $\mathrm{z}$-axis is verti-

cal. The spacing of the roll axes defines a roll wavelength, which is typically 2.4 to 4 times the PBL depth; this defines the typical roll aspect ratio.

The most commonly discussed feature of PBL rolls is the associated overturning $(V, W)$ circulation. This circulation produces a quasi-equilibrium secondary circulation (relative to the mean wind) in the form of counter-rotating vortices that

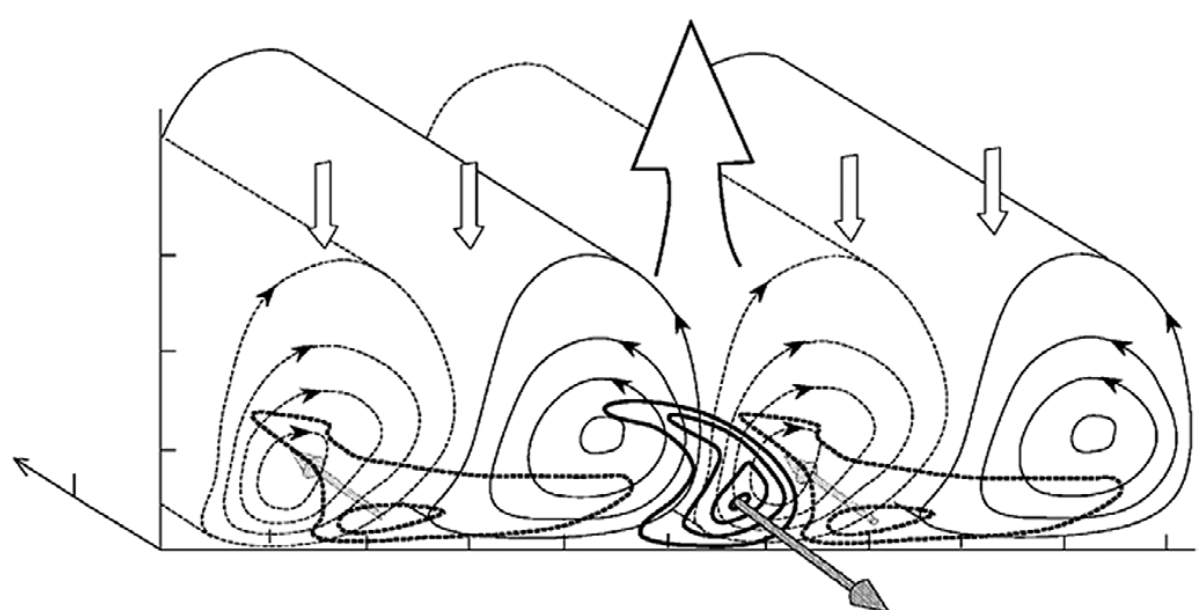

Figure 1. Schematic of a typical planetary boundary layer roll organized large eddy with organized large eddies. The view is looking downstream. Contours of the overturning stream function are shown (flow is counterclockwise around positive stream functions). Nearer the surface, contours of the along-roll flow are shown. Relatively strong local reductions in the surface wind fall below the relatively concentrated and stronger updrafts. Somewhat weaker local enhancements of the along-roll wind are underneath the broader downdraft regions.

span the depth of the PBL. The updrafts in this overturning flow are strongest in the mid-PBL and induce spatially linear updraft patterns with interspersed, broader downdrafts. When the meteorological conditions are favorable, lowlevel clouds form in the updrafts. Such low-level "cloud streets" are frequently seen in satellite or aircraft images over both land and water. However, it must be stressed that rolls are frequently present even when cloud streets do not form. The V-component of the roll circulation produces spatially periodic near-surface convergence beneath the updrafts and a broader divergence beneath the downdrafts. The strength of the overturning part of the roll flow is about 5 to $10 \%$ of the mean wind above the PBL, depending on the PBL stratification. Unstable stratification strengthens the roll circulation.

The strongest part of the roll OLE circulation is in the $U$ component, which ranges from about 10 to $25 \%$ of the mean above-PBL wind. The rollinduced $U$ perturbations are within the lowest third of the PBL, and they induce spatially periodic local enhancements and reductions of the mean surface wind. The near-surface wind speed is reduced near the bottom of the updraft lines and enhanced between them. This alternating enhancement and reduction of the surface wind speed induces a spatially periodic pattern in the surface wind stress curl.

PBL rolls form due to instabilities of the PBL mean state, which is determined by the vertical profiles of the mean horizontal wind vector and the vertical potential temperature (Lilly, 1966; Faller and Kaylor, 1967; Brown 1980; Etling and Brown, 1993; Foster 1996, 2005; Young 
et al., 2002). The instability mechanism is a combination of a dynamic instability and a convective (i.e., buoyancyrelated) instability. Rolls form when the convective instability mechanism tends to support the dynamical instability (i.e., near-neutral to moderately unstably stratified conditions). They are also an example of "cross-flow" instabilities because the instability is not associated with the stronger along-wind component of the PBL mean flow but rather with the turning component of the mean wind. This is why the rolls tend to align along the mean PBL vertical wind shear (Lilly, 1966; Brown 1970, 1972; Foster 1996, 2005; Foster and Levy, 1998).

\section{HURRICANE BOUNDARY}

\section{LAYER ROLL VORTICES}

Hurricanes represent one of the most extreme PBL environments. Because they form and mature over very warm SSTs, the total sensible plus latent heat (i.e., enthalpy) surface flux can be $O\left(1,000 \mathrm{~W} \mathrm{~m}^{2}\right)$ in the inner core (Zhang et al., 2009). Category-1 mean wind speed is $\sim 33 \mathrm{~m} \mathrm{~s}^{-1}(\sim 3.3 \mathrm{~Pa}$ surface stress), and winds over $20 \mathrm{~m} \mathrm{~s}^{-1}$ are found even 100 to $200 \mathrm{~km}$ from the storm center. Near-surface stratification is determined from the ratio of shear production of turbulence to buoyant production of turbulence, and the high wind speeds keep the hurricane inner-core PBL nearly neutrally stratified even in the presence of such extreme enthalpy fluxes. Thus, somewhat surprisingly given the intense turbulence, the hurricane boundary layer would seem to be a favorable environment for roll formation.

As mentioned above, Doppler radar analyses show that PBL roll vortices that tend to align close to the surface wind direction and that have subkilometer to multikilometer wavelengths, but nearly always at aspect ratios comparable to those seen in standard rolls, are a frequent feature of the hurricane boundary layer (Wurman and Winslow, 1998; Morrison et al., 2005; Lorsolo et al., 2008; Ellis and Businger, 2010). The dynamical hurricane boundary layer depth can be subkilometer near the storm center, and it tends to increase with increasing radius from the center (Zhang et al., 2011). The smallest-scale rolls may also be related to surface layer streaks (Foster, 1997; Drobinski and Foster, 2003; Foster et al., 2006).

Katsaros et al. (2002) analyzed hurricane surface wind-induced features in SAR imagery of hurricanes and found clear evidence of roll vortices in several images. Zhang et al. (2008) used twodimensional spectral analysis to show that PBL roll signatures in the SAR normalized backscatter are present throughout much of a SAR image of hurricane Isadore (2002). Horstmann et al. (2005) showed that the roll signature could be used to set the wind direction in SAR images of hurricanes. Horstmann et al. (2013, in this issue) combined maximum contrast and local gradient methods to determine the wind direction in hurricane SAR images from the imprint of linear streaks on the sea surface. Based on these different lines of evidence, we hypothesize that rolls with aspect ratios near 2.5 are usually present in the hurricane PBL.

Foster (2005) developed a nonlinear theory specific to the hurricane boundary layer to explain why the rolls should be considered the most likely mean state of the hurricane PBL away from the regions of intense convection such as rain bands. This analysis also predicted that the expected aspect ratio of the rolls should be $\sim 2.5$ and that the roll strength, as a percentage of the gradient wind above the PBL, is comparable to that of non-hurricane rolls.

\section{DIVERGENCE AND WIND STRESS CURL}

Horstmann et al. (2013, in this issue) describe the processing of SAR hurricane imagery into a $1 \mathrm{~km}$ surface wind vector product. The methodology is based on those of Horstmann and Koch (2005) and Wackerman et al. (1996). The primary challenge is to determine the wind direction. Horstmann et al. (2013, in this issue) combine a local gradient (mainly 0.4 to $2 \mathrm{~km}$ scale) method and a maximum contrast (mainly scales larger than $2 \mathrm{~km}$ ) method to estimate the surface wind direction at $1 \mathrm{~km}$ scales from the wind-induced streaks in the backscatter. The $1 \mathrm{~km}$ averaged backscatter and wind directions are then used as inputs to a geophysical model function that predicts the backscatter as a function of wind speed and viewing geometry. The linear features detected in the SAR backscatter are usually associated with PBL rolls (Gerling, 1986). Figure 2a shows a high-contrast image of the SAR backscatter for Hurricane Katrina on August 27, 2005. Figure 2b shows the derived surface wind field. Observations of hurricane wind directions have a large amount of scatter (Zhang and Uhlhorn, 2012); however, SAR wind directions are generally consistent with observational trends. The overall average SAR inflow angle for this image is $\sim 12^{\circ}$, and the inflow is larger than the average to the right of the storm track.

Figure $2 c$ shows a typical example 
of surface wind divergence calculated from the same SAR image of Hurricane Katrina. The most striking feature of this image is the presence of banded patterns of alternating convergence and divergence with a wavelength between 10 and $20 \mathrm{~km}$. These bands are roughly aligned along the mean surface wind direction and are present throughout the images. Figure $2 \mathrm{~d}$ shows the surface wind stress curl for the same image. As in Figure 2b, the wind stress curl is banded approximately along the mean wind direction at similar wavelengths. These surface wind convergence and wind stress curl patterns are typical: we found similar patterns in all of the 40 SAR images of tropical cyclones that we examined.

If the large aspect ratio banded features are induced by roll-like coherent structures, we would expect to find the convergence and divergence peaks between minima and maxima of the cross-roll wind. Similarly, the positive and negative wind stress curl features would be found between minima and maxima of the along-roll wind. We performed a one-dimensional continuous wavelet transformation (CWT) along the cross section shown in Figure 2 using Ricker wavelets. The surface winds along the cross section were approximately resolved into their along- and across-roll components by rotating the azimuthal/ tangential winds by one-half of the inflow angle. The CWT was applied to the cross-roll and along-roll winds, the divergence, and the wind stress curl. The spectrogram of the CWT shows

Katrina, August 27, 2005, 11:28
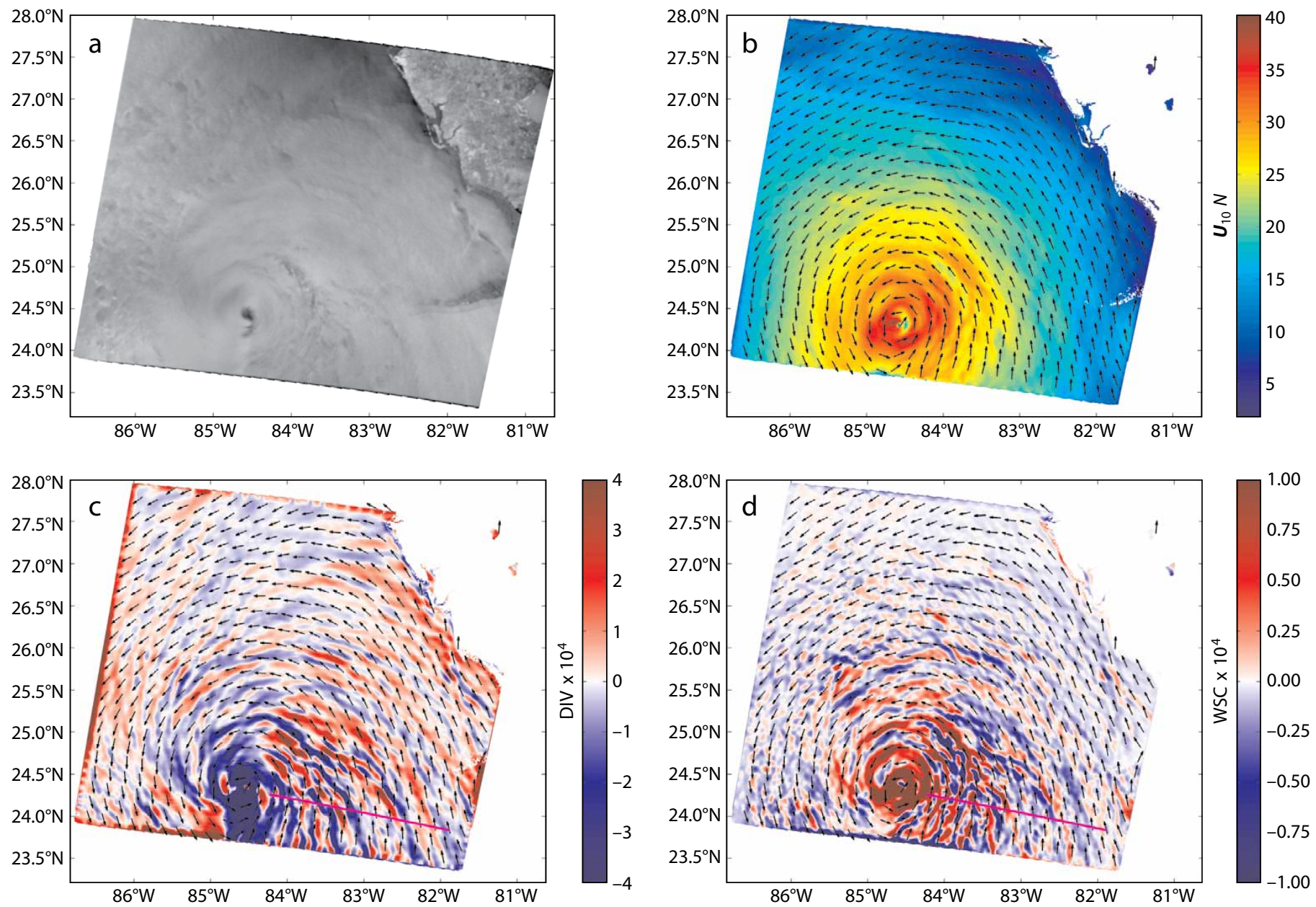

Figure 2. (a) Enhanced contrast synthetic aperture radar (SAR) backscatter image of Hurricane Katrina, August, 27, 2005, 11:38 UTC. (b) Surface wind estimated from the SAR image. (c) Surface wind divergence (multiplied by $10^{4}$ ) calculated from the surface wind vectors. (d) Surface wind stress curl (multiplied by $10^{4}$ ) from the surface wind vectors. All images are at $1 \mathrm{~km}$ pixels. Wind direction vectors are shown every $20 \mathrm{~km}$. The magenta line indicates where the data used in Figure 3 were taken. 
consistent organization at approximate local wavelengths between $\sim 8$ to $19 \mathrm{~km}$.

Figure 3 shows the coefficients of the wavelet corresponding to a local $13.4 \mathrm{~km}$ wavelength contribution. In Figure 3a, it is clear that the convergence and divergence tend to maximize between minima and maxima of the radial wind. Similarly, the minima and maxima of the wind stress curl tend to fall between the minima and maxima of the tangential wind (Figure 3b). Similar results are found for all of the wavelet coefficients within the 8 to $19 \mathrm{~km}$ wavelength band. These results strongly suggest that the $O(10 \mathrm{~km})$ wavelength banded features are associated with roll-like coherent structures. However, the mechanism by which such large aspect ratio OLE can form is unclear because the unstable normal modes corresponding to these large scales grow nearly an order of magnitude more slowly than the dominant hurricane PBL normal modes that generate roll vortices (Foster, 2005). Hence, by standard analysis methods, they would not be expected to survive competition with standard hurricane roll vortices.

\section{RESONANT TRIAD}

WAVE-WAVE MODEL

Cold-air outbreaks off the Arctic icepack are another example of an extreme PBL environment. The wind speeds are high as is the surface enthalpy flux, which results in a near-neutral boundary layer that is an excellent environment for the formation of roll OLE. Brummer and Pohlmann (2000) studied wintertime conditions and found roll-induced cloud streets about half the time in the Greenland and Barents Sea regions and no sign of cloud streets only $5 \%$ of the time. Walter and Overland (1984) found that the rolls in such conditions are a mixture of rolls at multiple wavelengths, some of which appeared to have very long wavelengths. Rolls corresponding to the dominant roll modes were also found.
Mourad and Brown (1990) developed a two-dimensional nonlinear resonant triad interaction model to explain the formation of the large aspect ratio roll modes in neutral stratification. The physical argument for the model is that the PBL is primed for the formation of low aspect ratio rolls, so that the basic state is a modified mean flow containing embedded primary roll modes. Larger and smaller wavelength rolls are unstable, but with significantly weaker growth rates. The primary mode roll growth is limited by nonlinear processes that include wave-mean flow interaction, generation of lower-amplitude harmonic components, and interactions between the primary and harmonic waves (Foster, 1996, 2005). For equilibrium rolls, these nonlinear effects act to halt the initially exponential growth of the instabilities.

Resonant triads are the fundamental building blocks of the nonlinear interactions between fluid motions at different scales. That is, the energy transferred a

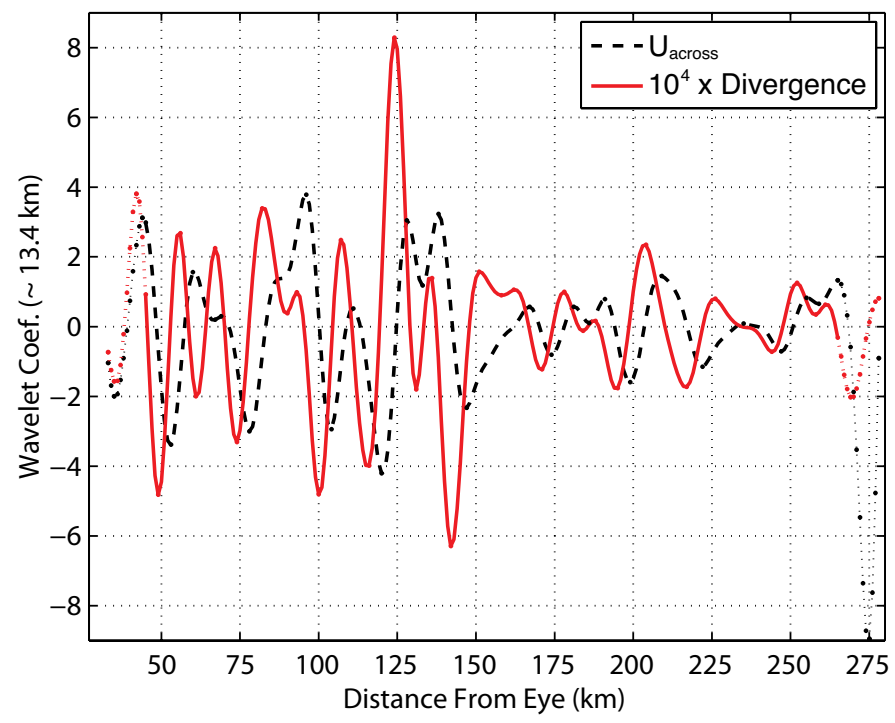

b

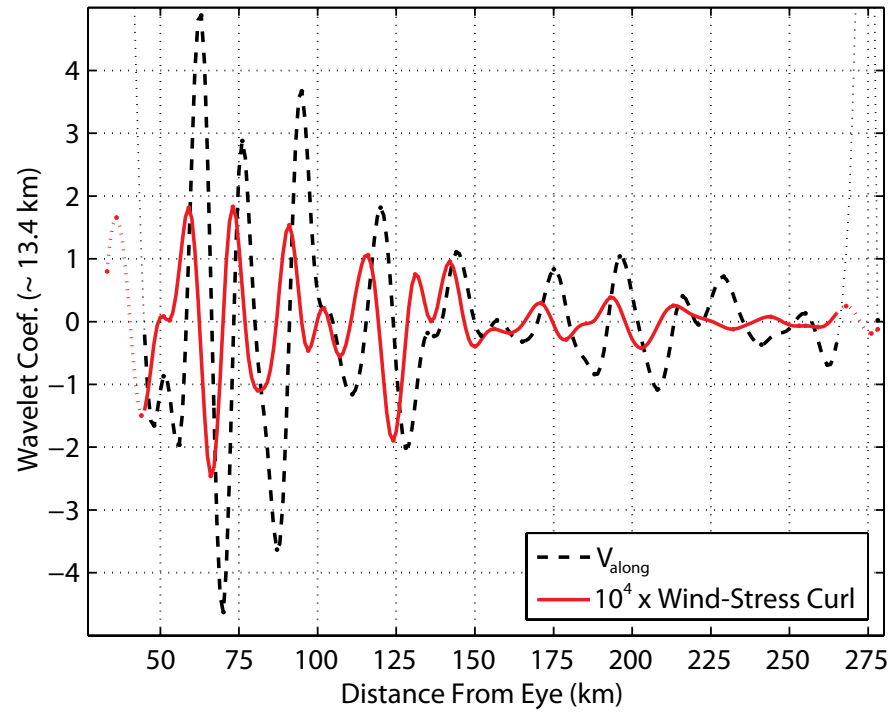

Figure 3. Coefficients of the approximately $13.4 \mathrm{~km}$ local wavelength wavelet taken from a continuous wavelet transform of the along-and across-roll wind components and of the surface wind divergence and wind stress curl. The wavelet coefficients are dotted where edge effects make the results questionable. (a) Divergence and across-roll wind component. (b) Wind stress curl and along-roll wind component. 
from motions of different spatial scales into or out of a particular mode comes from modes whose wave vectors form a triangle with the wave vector for the mode in question. The standard single-mode nonlinear stability analysis (e.g., Foster, 2005) will thus omit these "wave-wave interaction" pathways by which energy can flow into slowly growing modes. For a resonant triad of wavelengths (i.e., $1 / \lambda_{A}=1 / \lambda_{B}+1 / \lambda_{C}$ ), a new interaction arises in the nonlinear stability analysis that allows for the transfer of energy between the roll modes (e.g., Schmid and Henningson, 2001). Importantly, this between-mode coupling is of lower order (i.e., comes into play) before the nonlinear processes that act to equilibrate the growing roll mode. Mathematically, the initial linear instability growth is linear in roll amplitude, $A$, and the stabilizing nonlinear effects are third order in amplitude, $A^{3}$, so $A^{3} \ll A \ll 1$. When the instability mechanism is linear, the amplitude grows exponentially in time. The third-order nonlinear effects slow this exponential growth, which leads to a quasiequilibrium state with OLE embedded in a modified mean flow. The new nonlinear energy exchange terms are second order in amplitude. Thus, the initially slowestgrowing mode can receive a "kickstart" in amplitude while still in a quasi-linear growth phase. The energy transfer occurs when the phase imbalance between the three waves matches the phase of a nonlinear coefficient that depends on the initial mean flow profile of the PBL and the wavelengths of the triad modes. In fact, Mourad and Brown (1990) showed that such an energy transfer from the fastest-growing mode into the slowestgrowing mode (via the intermediate mode) must occur. By this mechanism, an initially slowly growing mode might reach finite amplitude much faster than its linear growth rate would predict. This may allow it to compete with the initially fastest growing mode in determining the quasi-steady solution.

The model of Mourad and Brown (1990) is two dimensional (overturning motions only) and is based on a pure Ekman boundary layer mean flow in neutral stratification. We have adapted the formalism to three-dimensional perturbations in a stratified mean flow. The nonlinear single-wave theory for hurricane roll vortices described in Foster (2005) was used as the starting point. The model in Foster (2005) was improved by incorporating the nonlinear hurricane boundary layer mean flow similarity model described in Foster (2009). As in Mourad and Brown (1990), we restricted the resulting resonant triad interaction model to co-linear modes and carried the expansion only to the third power in roll amplitude. As Foster (1996) shows, this is sufficient to understand the basic dynamics, but the solutions are less accurate than higher-order amplitude expansions.

In the hurricane PBL case, we know that roll OLE are the preferred mean state. Hence, we assume that rolls of wavelength $\lambda_{A}$, corresponding to the fastest-growing mode, are present. For the case of interest, $\lambda_{C}$ is the slowly growing, long-wavelength mode. $\lambda_{B}$ is an intermediate wavelength mode that has a growth rate between that of modes $A$ and $C$. Figure 4 shows a typical resulting solution snapshot from the quasiequilibrium state. The assumed basic state was a hurricane with maximum gradient wind speed of $40 \mathrm{~m} \mathrm{~s}^{-1}$ and a radius of maximum winds of $40 \mathrm{~km}$. The calculation was performed at twice the radius of maximum winds where the PBL depth was about 1,200 m. The gradient wind at this radius was $\sim 34 \mathrm{~m} \mathrm{~s}^{-1}$ ( $25 \mathrm{~m} \mathrm{~s}^{-1}$ surface wind), and the maximum inflow velocity was $\sim 10 \mathrm{~m} \mathrm{~s}^{-1}$.

These conditions are consistent with the composited observations presented in

Zhang et al. (2011).

The system reaches a quasiequilibrium condition in which all three modes are present and have equilibrated their amplitude growth. However, they continue to exchange energy and to propagate at different phase speeds, which leads to a variable mean state. The signature of the large wavelength mode is apparent, and it extends well above the top of the boundary layer, which is consistent with the observations of Gall et al. (1998). The other roll wavelengths are also present, and they modulate the surface signature of the largest wavelength roll mode. Note that the strong along-roll wind perturbations are confined to the lowest $\sim 400 \mathrm{~m}$ of the PBL and that their peak magnitudes are about $30 \%$ of the mean surface wind speed. However, low-order truncations tend to slightly overestimate the quasiequilibrium amplitudes.

\section{DISCUSSION}

Previous studies of hurricane SAR imagery (Katsaros et al., 2002; Li et al., 2013) have focused on identifying sea-surface signatures of roll OLE, rain, eyewall mesovortices, and storm morphology. With the advent of SAR wind retrieval technology in hurricane conditions, we have an unprecedented opportunity to examine details of the surface wind vector field in hurricanes. This has shown 
that, in addition to the well-known low aspect ratio hurricane roll vortices, it is quite likely that large aspect ratio roll vortices are also present throughout much of the inner core of the hurricane. The large-aspect ratio roll signature is clearest in surface wind stress curl and surface wind divergence. An independent study by Gall et al. (1998) found very similar features in the wind field above and in the upper regions of three hurricane boundary layers. We hypothesize that same large aspect ratio rolls induce both the SAR signatures and those in the study of Gall et al. (1998).

To test this idea, we constructed a nonlinear triad interaction model that incorporates nonlinear mean flow dynamics, three-dimensional perturbations, and stratification effects. The model produces a quasi-equilibrium state that is consistent with both the SAR and Doppler radar observations of large aspect ratio rolls. The model is also consistent with the previously documented low-aspect ratio hurricane boundary layer rolls.
The WSC and DIV signatures are present in all of the hurricane SAR images that we examined. Gall et al. (1998) hypothesized that the Doppler radar features are present in all strong hurricanes. The SAR data support that hypothesis and suggest that they are likely present in all hurricanes. This is a new view of the mean state of the hurricane PBL.

Before these results, we had the idea that low aspect ratio rolls, contained within the PBL, are nearly always present. Their effect on PBL fluxes is unclear. Zhang et al. (2008) demonstrated that OLE contributed about $50 \%$ to the low-level momentum flux in Hurricane Isadore (2002). There was evidence of a comparable signature in the humidity flux, but there was not an operating fast humidity sensor. Heat fluxes did not show a comparable OLE signature. However, French et al. (2007) did not find evidence of an OLE effect on the momentum flux in other hurricanes. Using a nested large eddy simulation, Zhu (2008) found that hurricane PBL rolls make a significant contribution to the total turbulent kinetic energy and fluxes. Furthermore, standard PBL parameterizations used in numerical models of hurricanes cannot capture their effects. Thus, even these low aspect ratio roll modes require further study.

Interestingly, Byrne and Zhang (2013) noted a transition in turbulence regimes between three dimensional (from largescale to small-scale turbulent energy transfer) and two dimensional (from small-scale to large-scale turbulent energy transfer) within the boundary layer of Hurricane Isabel (2003). The turbulence was three dimensional closer to the sea surface. Future research should explore the possible connection between these large aspect ratio OLE and local turbulence regimes.

Large aspect ratio rolls modulate and are modulated by low aspect ratio rolls. They also appear to routinely penetrate above the boundary layer. This provides a secondary circulation that connects the surface with the storm interior. No previous studies have investigated whether or
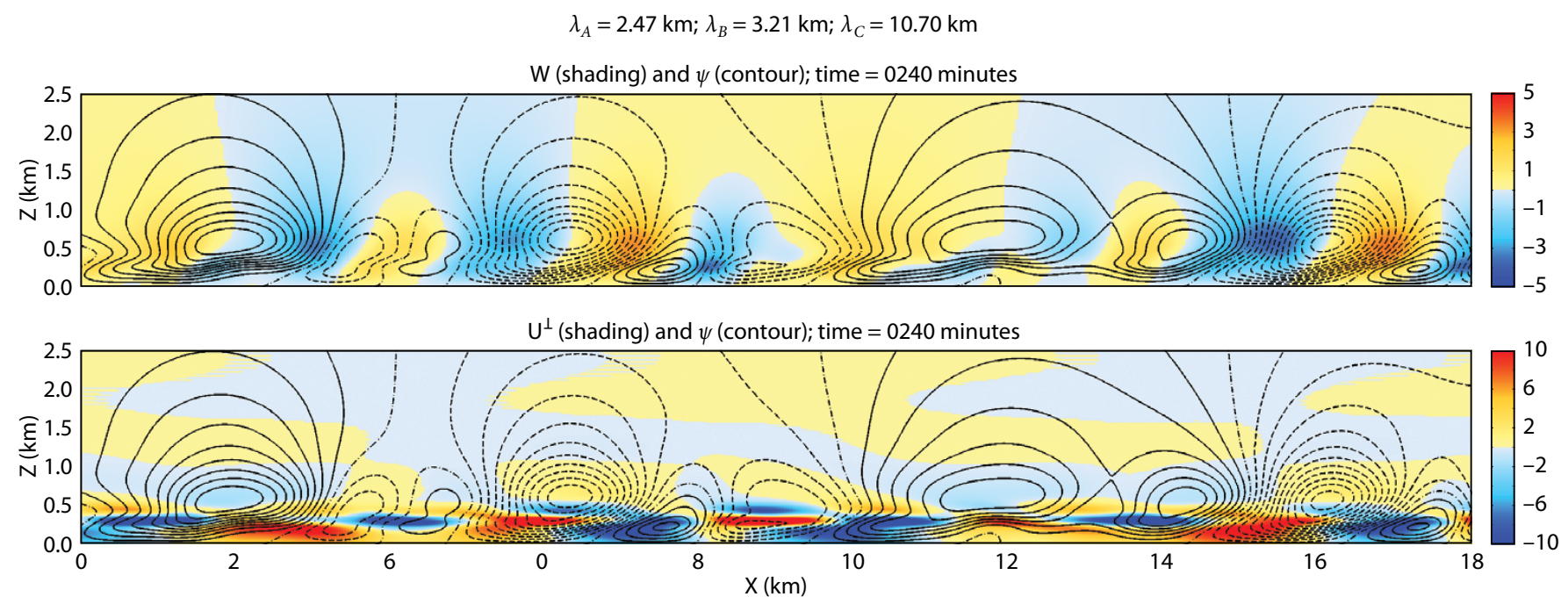

Figure 4. Typical quasi-equilibrium solution from the resonant triad hurricane roll model. In both panels, the line contours are the stream function describing the overturning flow. The flow is counterclockwise around the positive contours (solid contour lines). In the upper panel, shading shows the vertical velocity. In the lower panel, shading shows the along-roll perturbation velocity. Velocities are in meters per second. 
not such a circulation plays a role in hurricane air-sea interaction or in the communication of air-sea fluxes to the storm interior. This is worthy of further study.

The resolution of numerical models for hurricanes is reaching the $1 \mathrm{~km}$ scale, which, in principle, is capable of resolv- seen in upper boundary layer and lower troposphere winds in Doppler radar analyses of land-falling hurricanes. A nonlinear resonant triad interaction model shows that wave-wave interaction provides a mechanism by which such large aspect ratio roll modes that con-

THE UNPRECEDENTED SPATIAL RESOLUTION AND COVERAGE OF SAR WIND FIELDS PROVIDE A NEW VIEW OF AIR-SEA INTERACTION IN HURRICANES THAT SUGGESTS THE SURFACE WIND IS HIGHLY

\section{ORGANIZED AT MUCH LARGER SPATIAL SCALES THAN THE USUAL TURBULENCE LENGTH SCALE BASED ON THE BOUNDARY LAYER DEPTH.}

ing the large aspect ratio structures. However, these numerical models do not resolve the low aspect ratio roll OLE, and their PBL parameterizations are incapable of capturing their nonlocal contributions to the turbulent fluxes within the boundary layer (Zhu, 2008). Thus, if the hypothesis presented in this paper about the formation of the large aspect ratio structures is correct, then the lack of large aspect ratio OLE in the numerical models is to be expected. This presents another important avenue for future research and a possible stringent test of the accuracy of PBL parameterizations used in hurricane research.

\section{CONCLUSIONS}

Surface wind fields derived from SAR imagery taken in hurricanes routinely shows evidence of large aspect ratio roll vortices. Similar structures have been nect the surface and the flow above the boundary layer can reach quasiequilibrium and co-exist with the wellknown low aspect ratio roll modes in the hurricane boundary layer.

\section{ACKNOWLEDGEMENTS}

The original SAR image, (C2005

Canadian Space Agency, was provided as part of the announcement of opportunity for "Innovative Research and Development of Applications Using RADARSAT-1" and the RADARSAT Hurricane Applications Project (RHAP). Basic wind processing was performed by J. Horstmann (CMRE, La Spezia, Italy), C. Wackerman (General Dynamics, Ypsilanti, MI) and M. Caruso (CSTARS, Miami, FL). This research was funded by ONR via grants N00014-08-1165 and N000141-11-0448 and NASA via grant NNX10A087G. Thank you to
Jun Zhang and an anonymous referee for helpful comments and questions that improved the presentation of the results in this paper.

\section{REFERENCES}

Brown, R.A. 1970. A secondary flow model for the planetary boundary layer. Journal of the Atmospheric Sciences 27:742-757, http:// dx.doi.org/10.1175/1520-0469(1970)027 $<0742$ :ASFMFT>2.0.CO;2.

Brown, R.A. 1972. On the inflection point instability of a stratified Ekman boundary layer. Journal of the Atmospheric Sciences 29:850-859, http://dx.doi.org/10.1175/ 1520-0469(1972)029<0850:OTIPIO>2.0.CO;2.

Brown, R.A. 1980. Longitudinal instabilities and secondary flows in the planetary boundary layer: A review. Reviews of Geophysics and Space Physics 18:683-697, http://dx.doi.org/10.1029/ RG018i003p00683.

Brummer, B., and S. Pohlmann. 2000. Wintertime roll and cell convection over Greenland and Barents Sea regions: A climatology. Journal of Geophysical Research 105(D12):15,559-15,566, http://dx.doi.org/10.1029/1999JD900841.

Byrne, D., and J.A. Zhang. 2013. Height-dependent transition from 3-D to 2-D turbulence in the hurricane boundary layer. Geophysical Research Letters 40:1,439-1,442, http://dx.doi.org/ $10.1002 / g r l .50335$.

Drobinski, P., and R.C. Foster. 2003. On the origin of near-surface streaks in the neutrally-stratified planetary boundary layer. Boundary-Layer Meteorology 108:247-256, http://dx.doi.org/ 10.1023/A:1024100125735.

Ellis, R., and S. Businger. 2010. Helical circulations in the typhoon boundary layer. Journal of Geophysical Research 115, D06205, http:// dx.doi.org/10.1029/2009JD011819.

Etling, D., and R.A. Brown. 1993. Roll vortices in the planetary boundary layer: A review. Boundary-Layer Meteorology 65:215-248, http://dx.doi.org/10.1007/BF00705527.

Faller, A.J., and R.E. Kaylor. 1967. Instability of the Ekman spiral with applications to the planetary boundary layer. Physics of Fluids 10:212-219, http://dx.doi.org/10.1063/1.1762452.

Foster, R.C. 1996. An analytic model for planetary boundary layer roll vortices. $\mathrm{PhD}$ Thesis, University of Washington, Seattle, WA, 196 pp.

Foster, R.C. 1997. Structure and energetics of optimal Ekman layer perturbations. Journal of Fluid Mechanics 333:97-123, http://dx.doi.org/ 10.1017/S0022112096004107.

Foster, R.C. 2005. Why rolls are prevalent in the hurricane boundary layer. Journal of the Atmospheric Sciences 62:2,647-2,661, http:// dx.doi.org/10.1175/JAS3475.1. 
Foster, R.C. 2009. Boundary-layer similarity under an axisymmetric, gradient wind vortex. Boundary-Layer Meteorology 131:321-344, http://dx.doi.org/10.1007/s10546-009-9379-1.

Foster, R.C., and G. Levy. 1998. The contribution of organized roll vortices to the surface wind vector in baroclinic conditions. Journal of the Atmospheric Sciences 55:1,466-1,472, http://dx.doi.org/10.1175/1520-0469 (1998)055<1466:TCOORV >2.0.CO;2.

Foster, R.C., F. Vianey, P. Drobinski, and P. Carlotti. 2006. Near-surface coherent structures and the momentum flux in a large eddy simulation of the neutrally-stratified boundary layer. Boundary-Layer Meteorology 120:229-255, http://dx.doi.org/10.1007/s10546-006-9054-8.

French, J.R., W.M. Drennan, J.A. Zhang, and P.G. Black. 2007. Turbulent fluxes in the hurricane boundary layer. Part I: Momentum flux. Journal of the Atmospheric Sciences 63:1,089-1,102, http://dx.doi.org/ 10.1175/JAS3887.1.

Gall, R., J. Tuttle, and P. Hildebrand. 1998. Smallscale spiral bands observed in hurricanes Andrew, Hugo, and Erin. Monthly Weather Review 126:1,749-1,766, http://dx.doi.org/ 10.1175/1520-0493(1998)126<1749:SSSBOI > 2.0.CO;2.

Gerling, T.W. 1986. Structure of the surface wind field from the Seasat SAR. Journal of Geophysical Research 91:2,308-2,320, http:// dx.doi.org/10.1029/JC091iC02p02308.

Horstmann, J., and W. Koch. 2005. Measurement of ocean surface winds using synthetic aperture radars. IEEE Journal of Oceanic Engineering 30:508-515, http://dx.doi.org/ 10.1109/JOE.2005.857514.

Horstmann, J., D.R. Thompson, F. Monaldo, S. Iris, and H.C. Graber. 2005. Can synthetic aperture radars be used to estimate hurricane force winds? Geophysical Research Letters 32, L22801, http://dx.doi.org/10.1029/2005GL023992.

Horstmann, J., C. Wackerman, S. Falchetti, and S. Maresca. 2013. Tropical cyclone winds retrieved from synthetic aperture radar. Oceanography 26(2):46-57, http://dx.doi.org/ 10.5670/oceanog.2013.30.

Katsaros, K.B., P.W. Vachon, W.T. Liu, and P.G. Black. 2002. Microwave remote sensing of tropical cyclones from space. Journal of Oceanography 58:137-151, http://dx.doi.org/ 10.1023/A:1015884903180.

LeMone, M.A. 1973. The structure and dynamics of horizontal roll vortices in the planetary boundary layer. Journal of the Atmospheric Sciences 30:1,077-1,091, http://dx.doi.org/ 10.1175/1520-0469(1973)030<1077:TSADOH> 2.0.CO;2.

LeMone, M.A. 1976. Modulation of turbulence energy by longitudinal rolls in an unstable boundary layer. Journal of the Atmospheric
Sciences 33:1,308-1,320, http://dx.doi.org/ 10.1175/1520-0469(1976)033<1308:MOTEBL > 2.0.CO;2.

Li, X., J.A. Zhang, X. Yang, W.G. Pichel, M. DeMaria, D. Long, and Z. Li. 2013. Tropical cyclone morphology from spaceborne synthetic aperture radar. Bulletin of the American Meteorological Society 94:215-230, http:// dx.doi.org/10.1175/BAMS-D-11-00211.1.

Lilly, D.K. 1966. On the instability of Ekman boundary flow. Journal of the Atmospheric Sciences 23:481-494, http://dx.doi.org/10.1175/ 1520-0469(1966)023<0481:OTIOEB > 2.0.CO;2.

Lorsolo, S., J.L. Schroeder, P. Dodge, and F. Marks Jr. 2008. Observational study of hurricane boundary layer small-scale coherent structures. Monthly Weather Review 136:2,871-2,893, http://dx.doi.org/10.1175/2008MWR2273.1.

Morrison, I., S. Businger, F. Marks, P. Dodge, and J.A. Businger. 2005. An observational case for the prevalence of roll vortices in the hurricane boundary layer. Journal of the Atmospheric Sciences 62:2,662-2,673, http://dx.doi.org/ 10.1175/JAS3508.1.

Mourad, P.D., and R.A. Brown. 1990. Multiscale large eddy states in weakly stratified planetary boundary layers. Journal of the Atmospheric Sciences 47:414-438, http://dx.doi.org/10.1175/ 1520-0469(1990)047<0414:MLESIW>2.0.CO;2.

Schmid, P.J., and D.S. Henningson. 2001. Stability and Transition in Shear Flows. Springer Applied Mathematical Sciences, Book 142, 556 pp.

Wackerman, C.C., C. Rufenach, R.A. Shuchman, J.A. Johannessen, and K.L. Davidson. 1996. Wind vector retrieval using ERS-1 synthetic aperture radar imagery. IEEE Transactions on Geoscience and Remote Sensing 34(6):1,343-1,352, http://dx.doi.org/ $10.1109 / 36.544558$

Walter, B.A. Jr., and J.E. Overland. 1984. Observations of longitudinal rolls in a near neutral atmosphere. Monthly Weather Review 112:200-208, http://dx.doi.org/10.1175/ 1520-0493(1984)112<0200:OOLRIA > 2.0.CO;2.

Wurman, J., and J. Winslow. 1998. Intense subkilometer-scale boundary layer rolls observed in Hurricane Fran. Science 280:555-557, http:// dx.doi.org/10.1126/science.280.5363.555.

Young, G.S., D.A.R. Kristovich, M.R. Hjelmfelt, and R.C. Foster. 2002. Rolls, streets, waves, and more: A review of quasi-two-dimensional structures in the atmospheric boundary layer. Bulletin of the American Meteorological Society 83:997-1,001, http://dx.doi.org/10.1175/ 1520-0477(2002)083<0997:RSWAMA> 2.3.CO;2.

Zhang, J., K.B. Katsaros, P.G. Black, S. Lehner, J.R. French, and W.M. Drennan. 2008. Effects of roll vortices on turbulent fluxes in the hurricane boundary layer. Boundary-Layer Meteorology 128:173-189, http://dx.doi.org/ 10.1007/s10546-008-9281-2.
Zhang, J.A., W.M. Drennan, P.G. Black, and J.R. French. 2009. Turbulence structure of the hurricane boundary layer between the outer rain bands. Journal of the Atmospheric Sciences 66:2,455-2,467, http://dx.doi.org/ 10.1175/2009JAS2954.1.

Zhang, J.A., R.F. Rogers, D.S. Nolan, and F.D. Marks. 2011. On the characteristic height scales of the hurricane boundary layer. Monthly Weather Review 139:2,523-2,535, http:// dx.doi.org/10.1175/MWR-D-10-05017.1.

Zhang, J.A., and E.W. Uhlhorn. 2012. Hurricane sea surface inflow angle and an observationbased parametric model. Monthly Weather Review 140:3,587-3,605, http://dx.doi.org/ 10.1175/MWR-D-11-00339.1.

Zhu, P. 2008. Simulation and parameterization of the turbulent transport in the hurricane boundary layer by large eddies. Journal of Geophysical Research 113, D17104, http:// dx.doi.org/10.1029/2007JD009643. 